\title{
THE FEATURES OF APPLICATION OF COMPENSATION FOR NON-PECUNIARY DAMAGE IN LABOR DISPUTES
}

\author{
Teymuraz L. Pagava \\ Volgograd Institute of Management - Branch of Russian Presidential Academy of National Economy \\ and Public Administration, Volgograd, Russian Federation
}

Introduction: in the paper, the author conducted a study of the application of compensation for moral damage in case of violating the citizens' property rights in the performance of labor duties. The purpose of this issue is to analyze the doctrinal approaches to the application of civil law to labor relations, identify cases and problems of applying compensation for moral damage in defense of the violated property and labor rights of citizens, and propose solutions to the problems studied. In addition, the author established the property right of the employee, which is subject to protection using such a method of protection as compensation for moral damage this is the right to timely and full payment of wages. As part of the exercise of this right, the author identifies the problems related to the application of non-pecuniary damage compensation to these relations. Methods: the methodological framework for this work is a set of methods such as formal-logical and system analysis. Results: in the course of the study, the author develops a concept according to which it seems reasonable to apply civil law to labor relations of a private legal nature, unless special law provides otherwise. Conclusions: the study found that labor law allows the application of civil law, if it does not contradict the rules of special law. The author also proposes to make changes to the current labor and civil legislation. In particular, it is proposed to take into account the amount of the property damage caused, as well as other circumstances that deserve attention when determining the amount of compensation for non-pecuniary damage in cases of violation of the employee's property rights.

Key words: non-pecuniary damage, compensation, property rights, citizen, labor rights.

Citation. Pagava T.L. The Features of Application of Compensation for Non-Pecuniary Damage in Labor Disputes. Legal Concept, 2020, vol. 19, no. 1, pp. 60-63. (in Russian). DOI: https://doi.org/10.15688/lc.jvolsu.2020.1.7

\section{ОСОБЕННОСТИ ПРИМЕНЕНИЯ КОМПЕНСАЦИИ МОРАЛЬНОГО ВРЕДА В ТРУДОВЫХ СПОРАХ}

\author{
Теймураз Леванович Пагава \\ Волгоградский институт управления - филиал Российской академии народного хозяйства \\ и государственной службы при Президенте РФ, г. Волгоград, Российская Федерация
}

Введение: в статье автором проведено исследование вопроса применения компенсации морального вреда в случае нарушения имущественных прав граждан при выполнении трудовых обязанностей. В рамках рассматриваемого вопроса поставлена цель: проанализировать доктринальные подходы к вопросу о применении гражданского законодательства к трудовым правоотношениям, выявить случаи и проблемы применения компенсации морального вреда в защиту нарушенных имущественных трудовых прав граждан и предложить средства решения изученных проблем. Автором установлено имущественное право работника, которое подлежит защите с применением такого способа защиты, как компенсация морального вреда, - это право на своевременную и в полном объеме выплату заработной платы. В рамках реализации данного права автор устанавливает проблемы, связанные с применением к данным отношениям компенсации морального вреда. Методы: методологическую основу данной работы составляет совокупность таких методов, как формально-логический, а также системный анализ. Результаты: в ходе исследо- 
вания автором формируется концепция, согласно которой представляется разумным применение гражданского права к трудовым отношениям частноправового характера, если специальным законом не предусмотрено иное. Выводы: в ходе исследования установлено, что трудовое законодательство допускает применение норм гражданского законодательства, если это не противоречит нормам специального права. Также автором предлагается внести изменения в действующее трудовое и гражданское законодательство, в частности - при определении размера компенсации морального вреда в случаях нарушения имущественных прав работника учитывать размер причиненного имущественного ущерба, а также иные заслуживающие внимания обстоятельства.

Ключевые слова: моральный вред, компенсация, имущественные права, гражданин, трудовые права.

Цитирование. Пагава Т. Л. Особенности применения компенсации морального вреда в трудовых спорах // Legal Concept= Правовая парадигма. -2020. - T. 19, № 1. -C. 60-63. -DOI: https://doi.org/10.15688/lc.jvolsu.2020.1.7

\section{Введение}

Конституция Российской Федерации в ст. 45 декларирует, что каждый вправе защищать свои права и свободы всеми способами, не запрещенными законом. При этом в данной статье предусмотрено, что государство гарантирует защиту прав и законных интересов человека и гражданина. Действующее гражданское, как и трудовое, законодательство предусматривает компенсацию морального вреда как компенсационный способ защиты нарушенных прав граждан. В связи с этим представляется актуальным рассмотреть вопрос о соотношении гражданского и трудового законодательства на примере применения компенсации морального вреда в трудовых спорах.

\section{Соотношение гражданского и трудового права в России}

Трудовое право рассматривается как самостоятельная отрасль частного права. Однако придание этой отрасли самостоятельности не означает, что она базируется только на трудовом законодательстве (Трудовой кодекс РФ и иные нормативно-правовые акты, принимаемые для регулирования трудовых отношений). Это порождает следующую ситуацию: допускается ли применение отечественного гражданского законодательства к трудовым отношениям?

Представляется разумной позиция Р.А. Курбанова, который рассматривает трудовое право как комплексную отрасль, однако указывает: «...Действующее трудовое право основывается на том, что указанные правоотношения первоначально базируются на равенстве уча- стников. Это означает, что при заключении трудового договора участники имеют равные права и возможности в их реализации» [4, с. 14].

Предложенный Р.А. Курбановым подход является отражением складывающейся в отечественном праве современной концепции. Поскольку влияние государства на трудовые отношения неоспоримо, наличие таких признаков в трудовых отношениях, как свободное волеизъявление на заключение, изменение и расторжение трудового договора, квалифицируется как частноправовой характер данных отношений, что также требует дополнительного правового регулирования на основе норм цивильного права.

По мнению О.А. Архиповой и Т.Ю. Лузянина, нормы гражданского законодательства могут применяться в трудовом праве в силу наличия следующих причин:

1. В предмет ведения трудового права включены имущественные отношения, которые основаны на свободном выражении воли ее участников, равенстве и имущественной независимости участников рассматриваемых правоотношений (отношения, возникающие при выплате работнику заработной платы, персональная ответственность участников трудового договора и т. д.).

2. Как в гражданском, так и в трудовом праве имеются схожие методы, а также общие принципы регулирования данных отношений (равенство сторон, свобода договора, судебная защита нарушенных прав) [3, с. 108].

В связи с этим можно сделать вывод, что при условии исследования трудовых отношений частноправового характера представляется разумным учитывать положения гражданского права, когда действующее законода- 
тельство позволяет сделать это. Поскольку в трудовом законодательстве предусмотрена возможность воспользоваться компенсацией морального вреда, следовательно применение положений гражданского законодательства, регламентирующих особенность данного института, допускается.

\section{Применение компенсации}

\section{морального вреда в трудовых спорах}

Немаловажное значение имеет определение имущественных прав, которые в рамках осуществления трудовой деятельности работника подверглись нарушению.

В ходе анализа прав работника, предусмотренных ТК РФ, установлено, что к трудовым имущественным правам можно отнести только право на своевременную и в полном объеме выплату заработной платы. С учетом сложившейся судебной практики выявлены следующие случаи защиты данного права:

1. Взыскание заработной платы за дни вынужденного прогула и компенсация морального вреда [1].

2. Взыскание задолженности по заработной плате и компенсации морального вреда [2].

Во всех рассматриваемых случаях судами апелляционной инстанции была дана оценка фактических обстоятельств по делу. Однако в отдельных случаях суды либо не поясняли, в связи с чем суд пришел к выводу о разумности и обоснованности присужденной суммы компенсации, либо в качестве аргументов приводили абстрактные формулировки (фактические обстоятельства дела и т. д.).

\section{Выводы}

Подводя итог по данной проблеме, следует сформулировать следующие выводы:

1. Допускается применение норм цивильного права к трудовым отношениям при условии исследования трудовых отношений частноправового характера, когда специальным законом не установлено прямого запрета. Поскольку в трудовом законодательстве предусмотрена возможность воспользоваться компенсацией морального вреда при нарушении трудовых прав, следовательно применение положений гражданского законодательства, рег- ламентирующих особенности данного института, допускается.

2. Среди исследованных прав работника было выявлено одно имущественное право на своевременную и в полном объеме выплату заработной платы. Предлагается абз. 2 ст. 237 ТК РФ исключить и дополнить статью 1101 ГК РФ положением о том, что «при определении компенсации морального вреда необходимо устанавливать характер и степень причиненных потерпевшему физических и нравственных страданий, степень вины причинителя вреда и потерпевшего, стоимостное выражение причиненного имущественного вреда, индивидуальные особенности потерпевшего, а также иные заслуживающие внимания фактические обстоятельства причинения вреда».

\section{СПИСОК ЛИТЕРАТУРЫ}

1. Апелляционное определение Волгоградского областного суда от 06.09.2018 по делу № 3313291/2018. - Электрон. текстовые дан. - Режим доступа: http://www.consultant.ru/cons/cgi/online. cgi?req $=$ doc\&cacheid $=0125$ F74A9A5BF970A56E6C38 EB086433\&mode=backrefs\&SORTTYPE $=0$ \&BASENODE $=32911-39 \& \mathrm{ts}=1018155689621421676 \&$ base $=$ SOUG\& $n=149490 \& \mathrm{rnd}=\mathrm{C} 61118 \mathrm{~B} 550 \mathrm{EA}$ 03B 098287AC1CD0BA8DF\#5mc16x026rk (дата обращения: 22.09.2019). - Загл. с экрана.

2. Апелляционное определение Нижегородского областного суда от 09.04.2019 по делу № 333984/2019. - Электрон. текстовые дан. - Режим доступа: http://www.consultant.ru/cons/cgi/online.cgi? req $=$ doc\&cacheid=9841A1A94D7880B4DA01D4FA3F8 AC8CC\&mode $=$ backrefs\&SORTTYPE $=0 \&$ BASENODE $=$ $3290533 \&$ ts $=1018155689621421676 \&$ base $=$ SOPV \&n $=398145 \& \mathrm{rnd}=\mathrm{C} 61118 \mathrm{~B} 550 \mathrm{EA} 03 \mathrm{~B} 098287 \mathrm{AC} 1 \mathrm{CD} 0$ BA8DF\#1e708avey3e (дата обращения: 22.09.2019). Загл. с экрана.

3. Архипова, О. А. О применении гражданского законодательства в регулировании трудовых отношений / О. А. Архипова, Т. Ю. Лузянин // Вестник Томского государственного университета. Право. - 2016. - № 4 (22). - С. 107-119.

4. Трудовое право : учебник для академического бакалавриата / под общ. ред. Р. А. Курбанова. 3-е изд., перераб. и доп. - М. : Юрайт, 2018. -332 с.

\section{REFERENCES}

1. Apellyatsionnoe opredelenie Volgogradskogo oblastnogo suda ot 06.09.2018 po delu № 33-13291/ 
2018 [Appeal Ruling of the Volgograd Regional Court of September 6, 2018 in Case no. 33-13291/2018]. URL: http://www.consultant.ru/cons/cgi/online.cgi? req $=$ doc $\&$ cacheid $=0125$ F 74A9A5BF970A56 E6C38EB086433\&mode $=$ backrefs\&SORTTYPE $=$ 0\&BASENODE $=32911-39 \& \mathrm{ts}=1018155689621421676$ $\&$ base $=$ SOUG $\& n=149490 \&$ rnd $=$ C61118B550EA 03B098287AC1CD0BA8DF\#5mc16x026rk (accessed 22 September 2019).

2. Apellyatsionnoe opredelenie Nizhegorodskogo oblastnogo suda ot 09.04.2019 po delu № 33-3984/2019 [Appeal Ruling of the Nizhny Novgorod Regional Court of April 9, 2019 in Case no. 33-3984/2019]. URL: http:// www.consultant.ru/cons/cgi/online.cgi?req $=$ doc $\&$
cacheid=9841A1A94D7880B4DA01D4FA3F8AC8CC \&mode=backrefs\&SORTTYPE=0\&BASENODE=32905$33 \& t s=1018155689621421676 \&$ base $=$ SOPV\&n=398145\&rnd =C61118B550EA03B098287AC1CD0BA8DF\#1e708avey3e (accessed 22 September 2019).

3. Arhipova O.A., Luzyanin T.Yu. O primenenii grazhdanskogo zakonodatelstva $v$ regulirovanii trudovykh otnosheniy[On the Application of Civil Law in the Regulation of Labor Relations]. Vestnik Tomskogo gosudarstvennogo universiteta. Pravo, 2016, no. 4(22), pp. 107-119.

4. Kurbanov R.A., ed. Trudovoe pravo: uchebnik dlya akademicheskogo bakalavriata [Labor Law: The Textbook for Undergraduate Academic]. Moscow, Yurayt Publ., 2018. 332 p.

\section{Information About the Author}

Teymuraz L. Pagava, Postgraduate Student, Department of Civil Law Disciplines, Volgograd Institute of Management-Branch of Russian Presidential Academy of National Economy and Public Administration, Gagarina St., 8, 400131 Volgograd, Russian Federation, teymuraz94@rambler.ru, https://orcid.org/0000-0003-2199-3278

\section{Информация об авторе}

Теймураз Леванович Пагава, аспирант кафедры гражданско-правовых дисциплин, Волгоградский институт управления - филиал Российской академии народного хозяйства и государственной службы при Президенте РФ, ул. Гагарина, 8, 400131 г. Волгоград, Российская Федерация, teymuraz94@rambler.ru, https://orcid.org/0000-0003-2199-3278 